\title{
Algorithm development for individualized precision feeding of supplemental top dresses to influence feed efficiency of dairy cattle
}

\author{
V. C. Souza, ${ }^{1}$ D. M. Liebe, ${ }^{2}$ T. P. Price, ${ }^{2}$ M. D. Ellett, ${ }^{1}$ T. C. Davis, ${ }^{2}$ C. B. Gleason, ${ }^{2}$ K. M. Daniels, ${ }^{1}$ \\ and R. R. White ${ }^{2 *}$ \\ ${ }^{1}$ Department of Dairy Science, Virginia Tech, Blacksburg 24061 \\ ${ }^{2}$ Department of Animal and Poultry Sciences, Virginia Tech, Blacksburg 24061
}

\begin{abstract}
Individualized, precision feeding of dairy cattle may contribute to profitable and sustainable dairy production. Feeding strategies targeted at optimizing efficiency of individual cows, rather than groups of animals with similar characteristics, is a logical goal of individualized precision feeding. However, algorithms designed to make feeding recommendations for specific animals are scarce. The objective of this study was to develop and test 2 algorithms designed to improve feed efficiency of individual cows by supplementing total mixed rations (TMR) with varying types and amounts of topdressed feedstuffs. Twenty-four Holstein dairy cows were assigned to 1 of 3 treatment groups as follows: a control group fed a common TMR ad libitum, a group fed individually according to algorithm 1 , and a group fed individually according to algorithm 2. Algorithm 1 used a mixed-model approach with feed efficiency as the response variable and automated measurements of production parameters and top-dress type as dependent variables. Cow was treated as a random effect, and cow by top-dress interactions were included if significant. Algorithm 2 grouped cows based on top-dress response efficiency structure using a principal components and k-means clustering. Both algorithms were trained over a 36-d experimental period immediately before testing, and were updated weekly during the 35 -d testing period. Production performance responses for dry matter intake (DMI), milk yield, milk fat percentage and yield, milk protein percentage and yield, and feed efficiency were analyzed using a mixed-effects model with fixed effects for feeding algorithm, top dress, week, and the 2- and 3-way interactions among these variables. Milk protein percentage and feed efficiency were significantly affected by the 3-way interaction of top dress, algo-
\end{abstract}

Received June 8, 2021.

Accepted November 29, 2021.

*Corresponding author: rrwhite@vt.edu rithm, and week, and DMI tended to be affected by this 3-way interaction. Feeding algorithm did not affect milk yield, milk fat yield, or milk protein yield. However, feeding costs were reduced, and hence milk revenue increased on the algorithm-fed cows. The efficacy of feeding algorithms differed by top dress and time, and largely relied on DMI shifts to modulate feed efficiency. The net result, for the cumulative feeding groups, was that cows in the algorithm 1 and 2 groups earned over $\$ 0.45$ and $\$ 0.70$ more per head per day in comparison to cows on the TMR control, respectively. This study yielded 2 candidate approaches for efficiency-focused, individualized feeding recommendations. Refinement of algorithm selection, development, and training approaches are needed to maximize production parameters through individualized feeding.

Key words: individualized, algorithm, precision, feeding

\section{INTRODUCTION}

Innovative dairy farm technologies have increased operation productivity, decreased costs per cow, and contributed tremendously to the financial success of dairy farmers (El-Osta and Morehart, 2000). From a global study conducted in 2013, approximately 69\% of producers reported use of precision dairy technologies on farms [e.g., pedometers to monitor activity, collars to monitor rumination, sensors in the milking parlor to measure milk yield (MY) and conductivity of milk; Borchers and Bewley, 2015]. Of the producers that used precision technologies, MY, cow activity, and mastitis were the most common activities monitored with the precision management technologies (Borchers and Bewley, 2015). However, many dairy farmers felt that there was unused functionality in their precision management systems (Eastwood et al., 2016). These systems usually collect a variety of data on individual cows, but rarely is that data compiled and integrated to make informed decisions on how to more accurately feed or manage individuals. Because of the variability 
of feed efficiency (FE) among individuals (Guinguina et al., 2020), precision feeding systems may contribute to optimizing $\mathrm{FE}$ by feeding cows in an individualized manner. However, most current precision feeding systems do not treat cows as individuals, but rather focus on diet and ingredient recommendations for groups of animals with similar characteristics (e.g., bred heifers, high-milk-producing cows, low-milk-producing cows, and dry cows; Zanton and Heinrichs, 2008).

Individually feeding cows is common in research studies, but it is not a typical industry practice because it is costly and labor intensive. Using and compiling many forms of information on individual cows to make informed predictions of how to best feed cows as individuals is an approach likely to increase profitability of entire dairy herds, while simultaneously making better use of data collected on farms. Precision nutrition models have been shown to be capable of improving the performance of dairy farms by meeting nutritional requirements of dairy cows more effectively (Wang et al., 2000). Precision ration formulation is theoretically capable of affecting performance parameters, including positive increases in predicted MY (White and Capper, 2014). Similar modeling and precision formulation approaches could also be used to make feeding recommendations for individual cows based on real-time data already collected on many farms.

True individual feeding of the entirety of a cow's ration on farm would be costly and likely impractical to implement because of the investment needed in individual troughs (e.g., a Calan gate system). Although investing in technologies that include automated supplementation capacity represents a substantial upfront investment, such technologies may be more feasible than truly individually feeding an entire ration because they do not require invasive updates to pen or bunk space. Additionally, if automated supplementation contributes to improvements in $\mathrm{FE}$, the increases in profits may partially offset the technology cost. As such, feeding custom, individualized supplements to dairy cattle, in addition to a TMR, may be an economical way to improve feed efficiencies while minimizing labor costs. Each cow could be fed a common TMR and supplemented with a custom supplement through an automated individualized feeder. With the advent of newer parlor feeders and automated milking and feeding systems, it is becoming more feasible to invest in common infrastructure that allows for individualized supplementation of cows. The strategies attempted for individualized feeding in this study were intended to explore how the evolution of such automated individualized supplementation technologies might contribute to improving FE of cattle. Toward this long-term vision, the objective of this experiment was to test the efficacy of 2 feeding algorithms to learn strategies to influence FE of individually-fed dairy cows in comparison to regularly managed control animals.

\section{MATERIALS AND METHODS}

\section{Animals, Diets, and Housing}

All procedures involving animals were approved by the Institutional Animal Care and Use Committee of Virginia Tech (protocol \# 18-002). This experiment was conducted from March 27, 2019, to April 30, 2019, which corresponds to the testing period only.

Twenty-four Holstein dairy cows 12 primiparous and 12 multiparous; $710 \pm 88 \mathrm{~kg}$ of BW $( \pm \mathrm{SD}) ; 231 \pm 23$ DIM at the beginning of the study] were housed in a 16-stall pen within a freestall barn and fed once daily $(1300 \mathrm{~h})$ using a Calan gate system (American Calan Inc.). As described in Price et al. (2021), a 36-d training period consisting of cows being exposed to all diet options were tested as follows: TMR (control), TMR plus corn grain (CG), TMR plus soybean meal (SBM), or TMR plus grass hay $(\mathbf{G H})$ in a $4 \times 4$ replicated Latin square design. The algorithms used during the experimental testing period (described in detail below) queried this training data to develop individualized animal feeding recommendations based on the goal of increasing individual cow FE. The experimental design of both the training and testing periods are detailed in Figure 1. The quantity of material top dressed varied across each period over a gradual increase to target providing 0 to $20 \%$ of dietary $\mathrm{NE}_{\mathrm{L}}$ intake (Price et al., 2021). Because of the challenges (i.e., economic, practical, space) associated with implementing precision feeding strategies in real farm settings, we aimed to evaluate the minimum degree of substitution or supplementation necessary to affect FE. This approach was adopted with the idea that the daily supplement or substitution could be provided as part of the feed in the parlor or automated milking system, or from an automated feeding system. As such, we elected to replace no more than $20 \%$ of the dietary energy because the mass of feed associated with this level of supplementation was likely already above what could reasonably be fed by existing automated milking systems. Thus, to establish the energy replacement level of $20 \%$, we considered the amount of time cows would have available to consume the proposed supplements in the parlor, which is around 7 min (Castro et al., 2012; Bach and Cabrera, 2017). However, the quantities tested may be sufficient substitution to measurably affect FE. One cow was removed from the experiment on d 17 after aborting at $128 \mathrm{~d}$ bred, but the $17 \mathrm{~d}$ of available data on this cow were still used in the analyses. 


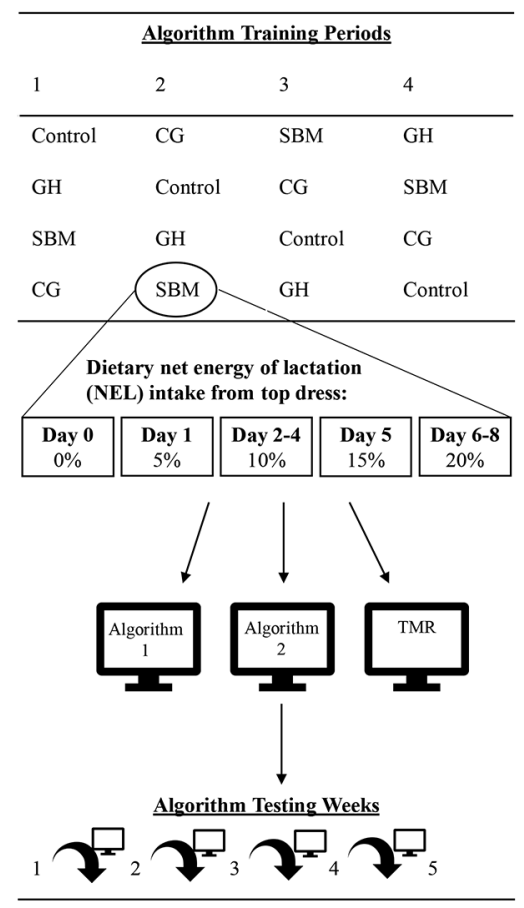

Algorithmic Development

Testing Period

Figure 1. The experimental design consisted of a training period, an algorithmic development period, and a testing period. The training period consisted of 4 periods that were $9 \mathrm{~d}$ in length as reported in Price et al. (2021). During each training period, 6 cows were randomly assigned to 1 of 4 top dress treatment options as follows: control $($ TMR only $)=$ TMR with no top dress; $\mathrm{CG}=\mathrm{TMR}$ with corn grain top dress; SBM = TMR with soybean meal top dress; or GH = TMR with mixed grass hay top dress. A replicated $4 \times 4$ Latin square was implemented, and each group of 6 cows was fed a different experimental treatment diet over the 4 periods. Throughout each period, cows were fed increasing amounts of dietary $\mathrm{NE}_{\mathrm{L}}$ intake from top dress. Two algorithms were then developed based off the training data that aimed to maximize individual cow feed efficiency. Eight cows were assigned to each algorithm, and 8 cows were assigned to an ad libitum control treatment (TMR only) to serve as the control group. During the 35-d testing period that followed the training period, algorithms were updated weekly in an attempt to make better predictions to positively affect individual cow feed efficiency.

A common TMR was fed as the base of all diets and was composed of mainly corn silage, corn grain, brewers grain, and soybean hulls (Table 1). The formulated composition of the common TMR fed to all treatment groups is detailed in Table 1. Each cow was fed ad libitum, and treatment diets were formulated to meet or exceed the requirements of each cow used throughout this trial based on their calculated nutrient requirements (NRC, 2001). The TMR provision was estimated from the animal's calculated $\mathrm{NE}_{\mathrm{L}}$ requirements using an excel spreadsheet containing the nutrient requirement equations from NRC (2001) to provide more specific individual estimation of nutrient requirements based on individual milk production. The amount offered was then adjusted on a daily basis to target 1.04 to $2.04 \mathrm{~kg}$ of refusals, daily. This adjustment to the mass of TMR provided to each animal daily increased the TMR by $5 \%$ per day if the running average refusal from the previous $2 \mathrm{~d}$ was less than $1.04 \mathrm{~kg}$. Similarly, the adjustment decreased the TMR mass provided by $5 \%$ per day if the running average refusal from the previous $2 \mathrm{~d}$ was greater than $2.04 \mathrm{~kg}$. The adjustments were capped such that animals could not be fed more than $1.5 \times$ their NRC-allocated TMR mass daily. Both algorithms were rederived on a weekly basis using the additional week of available data in an attempt to make better predictions for individual cow FE. All cows had ad libitum access to water throughout the experiment. Animal health and disposition were monitored daily throughout the study.

\section{Algorithm Development}

Each cow was randomly assigned to 1 of 3 treatment groups. The control group was managed according to normal farm practices and was fed a TMR ad libitum without top dress, as described below. The other 2 treatment groups represented different precision feeding approaches. The groups differed in the algorithm used to assign top-dress types and quantities to individual cows. Both algorithms were trained from data obtained from a 36-d training period, presented as a separate experiment (Price et al., 2021). The independent training period occurred immediately before the 35-d experimental algorithm testing period, which was used to generate the results presented in the present work (Figure 1).

Algorithm 1. The first algorithm aiming to provide individual feeding recommendations used a mixed-model approach. The data on DMI, MY, milk components, activity, and BW collected daily were paired with the treatment feeding schedule information to generate a data set that matched feed quantity and composition offered on the previous day with MY and composition data from the current day, following the logic that what we fed the cow yesterday was likely to affect her milk production and composition today. The response variable for all models used in this algorithm was FE (MY/ feed intake) expressed as a proportion of the maximum FE (FPM) displayed by that individual over the training data collection period. A unique mixed-effects model was derived for each top-dress type to describe how the daily sensed data interacted with top-dress type within an individual animal's data set to affect FE as FPM. Models followed the general structure:

$$
F P M_{i j}=\mu+\alpha_{i j}+\boldsymbol{\beta}_{i j k}+\alpha_{i j} \boldsymbol{\beta}_{i j k}+\epsilon_{i j}
$$


Table 1. Formulated composition of the common TMR fed to all treatment groups ${ }^{1}$

\begin{tabular}{|c|c|}
\hline Ingredient & $\begin{array}{c}\%, \mathrm{DM} \\
\text { basis }\end{array}$ \\
\hline Corn silage, brown midrib & 24.5 \\
\hline Alfalfa hay & 2.16 \\
\hline Brewers grain & 8.15 \\
\hline Corn grain, dry, ground & 10.8 \\
\hline Cottonseed, whole, with lint & 4.33 \\
\hline Milk cow concentrate & 25.0 \\
\hline Corn grain, dry, ground & 7.21 \\
\hline Soybean hulls, ground & 5.49 \\
\hline Canola meal & 4.03 \\
\hline Amino plus ${ }^{2}$ & 3.93 \\
\hline Palmit $80^{3}$ & 0.86 \\
\hline Blood meal, dried & 0.78 \\
\hline Sodium bicarbonate & 0.50 \\
\hline Limestone, ground & 0.50 \\
\hline Potassium carbonate & 0.43 \\
\hline Salt, white & 0.29 \\
\hline Volclay $90^{4}$ & 0.17 \\
\hline Molasses, cane & 0.13 \\
\hline OmniGen- $\mathrm{AF}^{5}$ & 0.17 \\
\hline Potassium magnesium sulfate & 0.09 \\
\hline MHA, dry $^{6}$ & 0.08 \\
\hline Calcium phosphate, mono-dicalcium phosphate & 0.07 \\
\hline Mepron $^{7}$ & 0.06 \\
\hline Diamond $\mathrm{XPC}^{8}$ & 0.04 \\
\hline Selenium yeast, $0.06 \%$ & 0.04 \\
\hline Ultrasorb $^{9}$ & 0.03 \\
\hline Clarifly $^{10}$ & 0.03 \\
\hline Biotin ${ }^{11}$ & 0.03 \\
\hline Zinpro $5^{12}$ & 0.02 \\
\hline Trace mineral blend & 0.02 \\
\hline Vitamin A, D, E blend & 0.01 \\
\hline Vitamin E premix, $60 \%$ & 0.01 \\
\hline Rumensin $90^{13}$ & 0.003 \\
\hline Total & 100.0 \\
\hline
\end{tabular}

${ }^{1}$ TMR formulated to provide $61.7 \mathrm{mCal}$ of ME per day; $2,750 \mathrm{~g}$ of MP per day; $39.0 \mathrm{~kg}$ of ME allowable milk per day; and $39.0 \mathrm{~kg}$ of MP allowable milk per day.

${ }^{2}$ Rumen protected soybean meal; Ag Processing, Inc.

${ }^{3}$ Vegetable palm oil; rumen bypass fat; ADM Animal Nutrition.

${ }^{4}$ Granular sodium bentonite; binder and digestive aid; American Colloid Company.

${ }^{5}$ Immune support supplement; microbial ingredients, vitamins, and aluminosilicates; Phibro Animal Health Corporation.

${ }^{6}$ Granular formulation of Alimet; 84\% methionine activity and $100 \%$ absorbed; NOVUS.

${ }^{7}$ Rumen-protected DL-methionine; RP Nutrients, Inc.

${ }^{8}$ Saccharomyces cerevisiae fermentation product; Diamond V.

${ }^{9}$ Mycotoxin deactivator; Micron Bio-Systems Ltd.

${ }^{10}$ Diflubenzuron feed-through fly control; Central Garden and Pet Company - Central Life Sciences.

${ }^{11} 2,200 \mathrm{mg}$ of biotin $/ \mathrm{kg}$.

${ }^{12}$ Trace mineral concentrate containing $30,688.51 \mathrm{mg} / \mathrm{kg}$ manganese, $5,370.57 \mathrm{mg} / \mathrm{kg}$ copper, $306.30 \mathrm{mg} / \mathrm{kg}$ iron, $75,187.97 \mathrm{mg} / \mathrm{kg}$ zinc, $613.32 \mathrm{mg} / \mathrm{kg}$ iodine, and $1,687.43 \mathrm{mg} / \mathrm{kg}$ cobalt (DM basis); Zinpro Performance Minerals.

${ }^{13}$ Monensin sodium energy supplement for increased milk production efficiency; Elanco Animal Health. where $F P M_{i j}$ is the $\mathrm{FE}$ of the $i$ th cow on the $j$ th day as a percent of that individual cow's maximum $\mathrm{FE} ; \mu$ is the overall mean; $\alpha_{i j}$ is the effect of intake of top dress of cow $i$ on day $j ; \boldsymbol{\beta}_{i j k}$ is a vector of $k$ parameters measured for animal $i$ on day $j$ [including animal ID, DIM, MY (kg), milk fat (\%), milk protein (\%), blood in milk (\%), daily activity (steps), and pregnancy status]; $\alpha_{i j} \beta_{i j k}$ are the interactions between treatment of cow $i$ on day $j$ and the individual explanatory variables $k$ measured on cow $i$ on day $j$; and $\epsilon_{i j}$ is the error term for the FPM measured on cow $i$ on day $j$. Each time models were derived, variables were removed for nonsignificance using a stepwise, backward elimination procedure. Nonsignificant main effects involved in significant interactions were retained even if $P>0.10$. Once a model was derived where all variables were either significant $(P<0.05)$, tending toward significance $(P<0.10)$, or involved in significant interactions, the model was considered final. Models were rederived weekly, and a unique model was developed for each top-dress type using the data obtained while the animal was consuming that top-dress. Final models by week and top-dress type are reported in Table 2, and the patterns of significance are discussed in the Results and Discussion section.

Once derived, the models were used to predict FPM for each cow based on their production records from the previous week and assuming they would be fed 0,5 , 10,15 , or $20 \%$ of their dietary energy as each top dress. The resulting prediction matrix created 20 predictions of FPM (4 feeding strategies $\times 5$ feeding levels), which were then screened to identify the feeding scenario (top-dress type and feeding level) required to obtain the maximum predicted FPM for each individual cow. The top-dress type and level that produced the highest predicted FPM for each individual cow were used as the feeding strategy for that cow for the subsequent week. Eight of the 24 cows were randomly assigned to this feeding approach.

Algorithm 2. The second algorithm aimed to differentiate cows by FE response structure in terms of feed-to-milk ratio (FtM). The FtM was calculated as feed intake per unit of MY, where a lower FtM was considered more efficient. Data were standardized to the percentage of maximum FtM for each individual cow over the entire experimental period. Principal component analysis (PCA) was used for each top dress to discern clusters of similar cows and make feed recommendations based on the resulting FtM. Each FtM record was calculated using the previous day's feeding record and the current day's MY. We did not assume any relationship a priori between the records from different days of a given cow's diet. The aim of PCA is to reduce dimensionality of data to better summarize 
Table 2. Weekly variables included in algorithm 1 models for each treatment

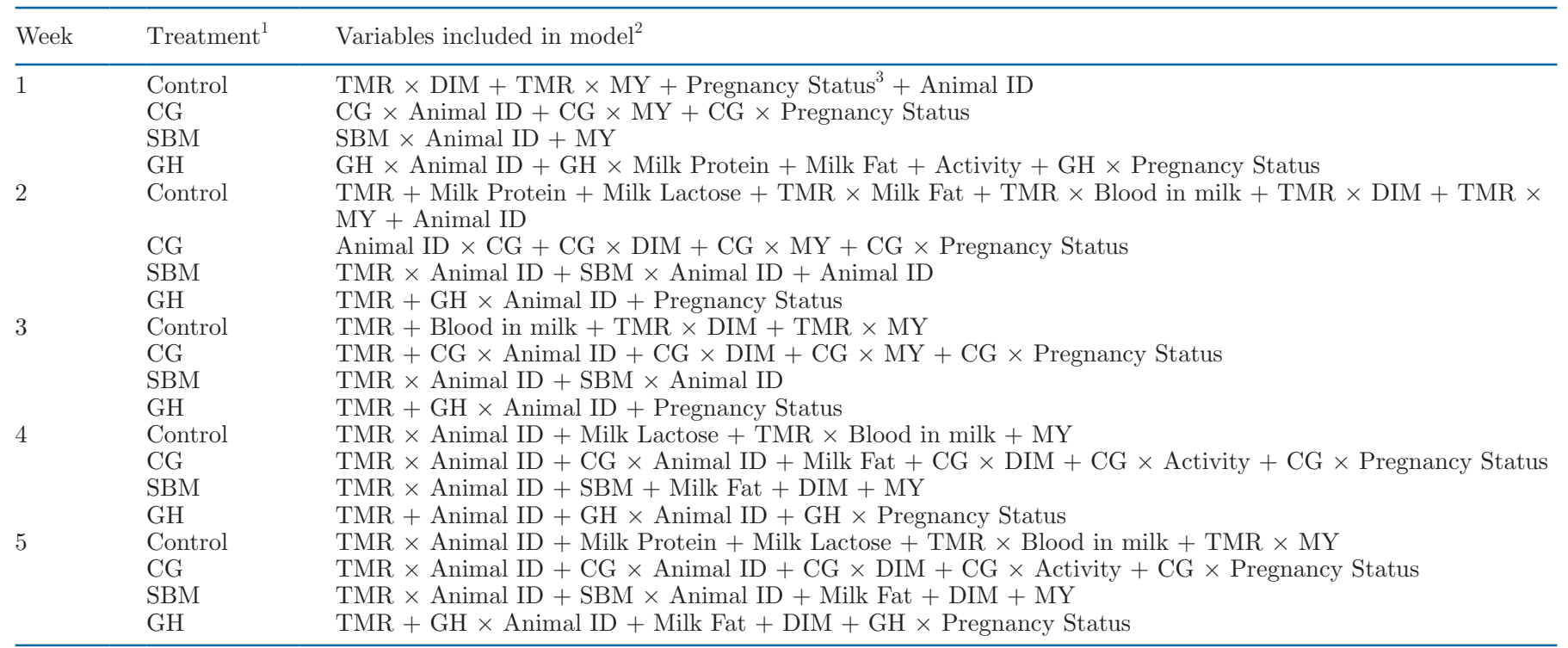

${ }^{1}$ Treatments: control $=$ TMR with no top dress; CG $=$ TMR with corn grain top dress; SBM $=$ TMR with soybean meal top dress; GH $=$ TMR with mixed grass hay top dress.

${ }^{2}$ Lactose variables recorded from AfiLab that seem to be miscalibrated were included in the model.

${ }^{3}$ Pregnancy status was a categorical factor with levels for bred, open, pregnant, and do not breed.

important variables. The first 2 dimensions of PCA were used with each of the 4 top dresses because variance was sufficiently explained by these components in all cases. The proportion of variance explained by each axis is typically plotted in a screen plot, which depicts each eigenvector of the covariance matrix divided by the sum of diagonal values in the covariance matrix. Correlations between each day's weight in the linear combination of variables used for each dimension in the PCA were recorded (Table 3). Based on the correlations between principal components and FtM responses by day, all responses had an influence on principal component 1, whereas d 1 and 4 had the greatest correlations with component 2 . Therefore, $\mathrm{d} 1$ and 4 appeared to be the greatest differentiator between cows' FtM responses. The use of only 2 dimensions also allowed for visual evaluation of clustering in the behavior of each cow's efficiency on each top dress. An example plot of PCA run on all cows fed the GH top dress is shown in Figure 2.

After performing PCA on each top dress using all 24 cows' FtM records, $k$-means clustering was used to systematically group cows based on their responses. The $k$-means clustering aims to group data points into $k$ groups such that the within-group mean distance is minimized. The resulting centroids, or centers of each cluster, create boundaries in the 2-dimensional PCA space where any given point inside that boundary is

Table 3. Correlations between the feed-to-milk ratio (FtM) on each day of feeding and principal components (PC) 1 and 2 for each of the top dresses fed over d 0 to $7^{1}$

\begin{tabular}{|c|c|c|c|c|c|c|c|c|}
\hline \multirow[b]{2}{*}{ Day } & \multicolumn{2}{|c|}{ Control } & \multicolumn{2}{|c|}{ Corn grain } & \multicolumn{2}{|c|}{ Soybean meal } & \multicolumn{2}{|c|}{ Grass hay } \\
\hline & PC1 & $\mathrm{PC} 2$ & $\mathrm{PC} 1$ & $\mathrm{PC} 2$ & $\mathrm{PC} 1$ & $\mathrm{PC} 2$ & PC1 & $\mathrm{PC} 2$ \\
\hline 0 & 0.80 & -0.06 & 0.90 & 0.28 & -0.77 & -0.14 & 0.76 & -0.15 \\
\hline 1 & 0.72 & -0.60 & 0.86 & 0.21 & -0.54 & 0.81 & 0.62 & 0.72 \\
\hline 2 & 0.81 & 0.54 & 0.92 & -0.01 & -0.93 & 0.13 & 0.84 & -0.20 \\
\hline 3 & 0.78 & 0.51 & 0.87 & 0.31 & -0.87 & 0.14 & 0.81 & -0.40 \\
\hline 4 & 0.90 & 0.13 & 0.86 & -0.41 & -0.90 & -0.21 & 0.78 & -0.33 \\
\hline 5 & 0.88 & -0.02 & 0.86 & 0.06 & -0.86 & -0.12 & 0.73 & -0.23 \\
\hline 6 & 0.87 & -0.32 & 0.85 & -0.38 & -0.80 & -0.40 & 0.76 & 0.13 \\
\hline 7 & 0.83 & -0.24 & 0.91 & 0.01 & -0.73 & -0.17 & 0.84 & 0.14 \\
\hline
\end{tabular}

${ }^{1} \mathrm{PC}$ were derived from a PC analysis of the FtM response of feeding each top dress to cows for $8 \mathrm{~d}$. 


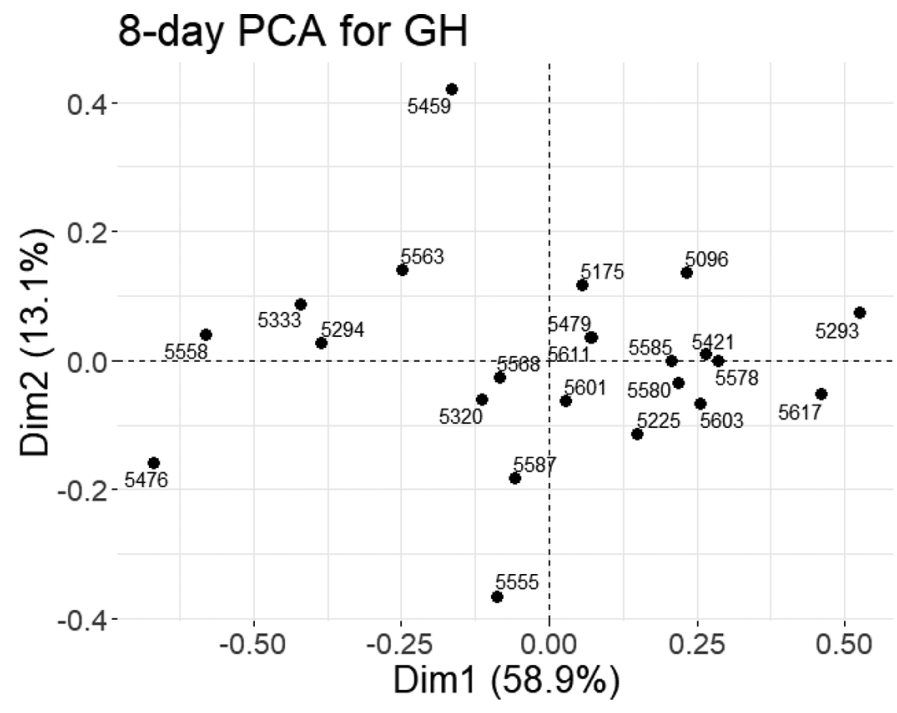

Figure 2. Principal components 1 (Dim1) and 2 (Dim2) derived from principal component analysis (PCA) of each cow's feed-to-milk conversion ratio response to the grass hay top dress. Each cow is represented by one point on the scatterplot, with the cow's ID number appearing next to its respective point. $\mathrm{GH}=\mathrm{TMR}$ with mixed grass hay top dress.

closer to one centroid than all others. Different values for $k$ were explored from 2 to 8 , with the optimal number of clusters being that which reduced the within-group sum of squared (WGSS) distances most, while keeping the total number of groups relatively low. Optimizing groups in $k$-means was done by finding the "elbow" in the plot of WGSS by cluster number, where the drop in WGSS levels off and additional groups only provide minimal distance reductions. For TMR, CG, SBM, and $\mathrm{GH}$, the chosen numbers of groups based on $k$-means evaluation to sufficiently partition cow feeding patterns were $4,2,3$, and 4 , respectively. An example PCA plot with groups annotated is shown for the GH top dress in Figure 3. With each cow grouped by each top dress, the mean FtM values for each group were assigned to all cows in a given group, resulting in each cow having 4 assigned FtM values, one for each top dress. Cows were then assigned a top dress based on which of their 4 assigned groups had the lowest mean group FtM. Eight of the 24 cows were randomly assigned to be fed using this approach.

TMR. The remaining 8 cows were randomly assigned to the TMR treatment. These animals were fed solely TMR ad libitum, with no additional top dress (Table 1). This treatment acted as the control and offered a baseline for comparing algorithms 1 and 2 . This treatment also represented a typical dairy feeding operation without individualized intervention aimed at improving FE.

\section{Feeding Procedure}

The feeding regimen over this experimental testing period was the same for the preceding experiment used for algorithm training (Price et al., 2021). Briefly, refusal sampling and feeding began daily at $1300 \mathrm{~h}$. and lasted, on average, $2.5 \mathrm{~h}$. All cows were allowed to eat their custom rations shortly after their afternoon milking that took place at $1400 \mathrm{~h}$. The Calan data ranger (American Calan Inc.) was used to remove and weigh refusals from each bunk and to dispense the target amount of TMR into each bunk. The TMR was dispensed within approximately $2.5 \mathrm{~kg}$ (as-fed basis) in either direction of the target TMR amount for each cow. The specified supplemental top dress for each cow was weighed by hand on a digital platform scale (Defender 5000 XtremeW, model T51XW; Ohaus Corp.). The top dresses were thoroughly mixed by hand to incorporate all of the top dress into the top third of TMR in each Calan bunk.

\section{Milking Procedure}

The milking procedure over this experimental testing period was also the same as in the preceding experiment (Price et al., 2021). In summary, all cows were milked twice daily, approximately every $12 \mathrm{~h}$ at 1300 and $0100 \mathrm{~h}$, in a double-12 De Laval parallel parlor (Dairymen Specialties Inc.). This parlor was equipped with an inline AfiMilk MPC Milk Meter (Afimilk Ltd.)

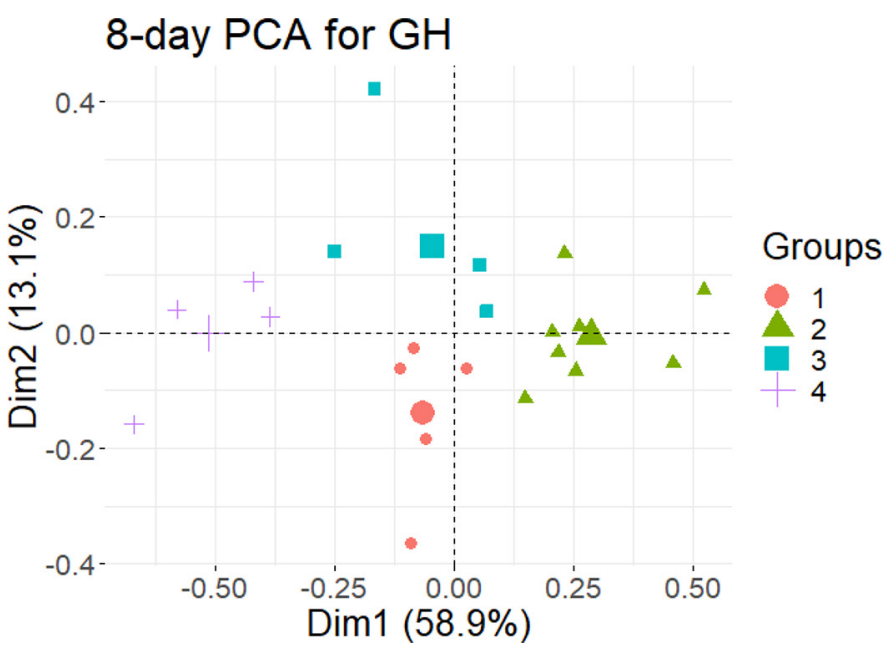

Figure 3. Scatterplot of principal components 1 (Dim1) and 2 (Dim2) for each cow in the study based on the principal components analysis (PCA) of their response to grass hay top dress. Four groups are divided based on $k$-means clustering of the Dim1 and Dim2 coordinates. The larger symbol in each group plotted represents the centroid coordinates of that group. GH = TMR with mixed grass hay top dress. 
for monitoring individual cow MY, and an AfiLab Milk Analyzer (Afimilk Ltd.) for inline individual cow milk composition analysis (blood, fat, protein, and lactose). Data on milk lactose was collected by the AfiLab Milk Analyzer, and was used in algorithm development, but this data did not correspond to biologically sensible values and suggests calibration errors in the AfiLab system. As a result, we have elected not to include milk lactose as a production performance response. Each cow was also equipped with a pedometer or activity monitor on one hind leg with embedded radiofrequency identification technology (AfiAct II Leg Tag; Afimilk Ltd.). These monitors recorded the number of steps taken daily for each cow. Data obtained from the pedometers were reported in 12 -h periods to match the milking events. After milking, the cows exited the parlor through an exit alley containing a walkover BW scale and radiofrequency identification reader (AfiWeigh; Afimilk Ltd.). Individual cow BW were recorded twice daily in association with milking, and these data were autocompiled into the AfiFarm dairy farm management software.

\section{Sample Collection and Analysis}

Samples of TMR and GH were collected daily and composited into 7-d samples that corresponded to the 7-d periods between algorithm updates. Because only 1 load each of CG and SBM (Big Spring Mill Inc.) were used throughout the entire experiment, these feeds were sampled only once after delivery to the farm. When sufficient orts were available ( $\sim 500 \mathrm{~g}$, as-fed basis), refusal samples were collected daily before feeding using the quartering method (ServiTech Laboratories, 2021). All samples were placed into zip-top plastic bags, labeled, and then frozen at $-20^{\circ} \mathrm{C}$ until analysis. Before analysis, individual cow refusal samples were thawed, pooled within each cow over 7-d periods, and subsequently processed in the same manner as previously described (Price et al., 2021). In short, all samples were ground with a model 4 Wiley mill to pass through a 1-mm screen (A. H. Thomas Scientific) and analyzed for DM (method 934.01), CP (method 968.06), NDF (method 2002.04), ADF (method 973.18), ash (method 942.05), ether extract (method 920.39), starch (method 920.40), and ADL (method 973.18) according to the methods described in AOAC (1990). The chemical composition of individual feedstuffs, including TMR, CG, SBM, and GH, are shown in Table 4. The CP content of the CG was unrealistically high. To better understand if this $\mathrm{CP}$ content was truly representative of what animals were consuming, we back-calculated the $\mathrm{CP}$ content of the feed using the analyzed diet samples and the analyzed refusal samples. In each instance, we found
Table 4. Chemical composition of TMR, corn grain (CG), soybean meal (SBM), and grass hay (GH) feedstuffs (\% of DM unless otherwise stated)

\begin{tabular}{lcccc}
\hline Item & TMR & CG & SBM & GH \\
\hline DM & 46.7 & 84.3 & 81.6 & 92.8 \\
CP & 15.1 & $21.2^{1}$ & 51.7 & 6.80 \\
NDF & 39.7 & 13.4 & 9.80 & 73.8 \\
ADF & 22.1 & 3.70 & 4.60 & 44.3 \\
Ash & 6.10 & 4.30 & 10.1 & 7.20 \\
Ether extract & 4.70 & 0.00 & 1.60 & 2.30 \\
Starch & 19.3 & 51.8 & 3.70 & 1.60 \\
ADL & 2.40 & 0.60 & 0.40 & 5.40 \\
\hline
\end{tabular}

${ }^{1}$ Suspected to be higher than typical values due to contamination during storage.

similar values $(<2$-percentage-unit difference) in the estimated CP content of this top dress. Based on this exercise, it appeared that the CG fed in this experiment was likely contaminated with a higher protein ingredient. As such, the results should not be taken to reflect responses associated with top-dressed CG alone and should be assumed to represent top dressing with a CG protein commodity mixture.

\section{Statistical Analyses}

Outcomes of interest included DMI, MY, milk fat percentage, milk fat yield, milk protein percentage, milk protein yield, and FE. All variables were analyzed in $\mathrm{R}$ version 3.5.2 (https://www.r-project.org/) using a mixed-effects model with fixed effects for feeding algorithm, top-dress, week, and the 2- and 3-way interactions among these variables. An effect for the initial level of the response variable (from the adaptation to the training period) was also included. A random effect for animal was included. Comparisons across treatments during the testing period and targeted contrasts back to TMR were used for mean separation. Least squares means were calculated, and comparison of means was based on contrasts between the treatment groups (algorithm by top-dress type) and the control group (TMR cows), within or across weeks (as appropriate given the significance of the various interactions involving time). Significant differences between treatments were declared at $P<0.05$, and significant interactions were declared at $P<0.10$.

\section{Financial Analysis}

To better understand the financial ramifications of the different feeding algorithms, the milk revenue garnered from cattle on each treatment, and the actual feed expenses associated with the different feeding strategies were collated to estimate feed costs, revenues, and milk revenue over feed costs. Feed cost $(\$ /$ head per day) 
was calculated by multiplying the total feed consumed $(\mathrm{kg} / \mathrm{d})$ by its respective cost $(\$ / \mathrm{kg}$, as feed). Milk revenues $(\$ /$ head per day) were calculated by multiplying milk production $(\mathrm{kg} / \mathrm{d})$ by milk price $(\$ / \mathrm{kg})$. Milk revenue over feed costs ( $\$ /$ head per day) was calculated by subtracting feed cost from milk revenues. Market source used for feed commodities was Big Spring Mill (Elliston, VA). Milk prices were those paid by the State of Virginia under an annually negotiated contract. Actual purchase costs for TMR $(\$ 0.22 / \mathrm{kg})$, corn grain $(\$ 0.231 / \mathrm{kg})$, soybean meal $(\$ 0.434 / \mathrm{kg})$, and grass hays $(\$ 0.165 / \mathrm{kg})$ fed on the study were used to estimate feed costs; receipts for milk sales $(\$ 0.396 / \mathrm{kg})$ were used to estimate milk revenues. All cow records were used in the financial analysis, but costs were standardized to number of animal days per treatment to account for cows removed from the study or missing records.

\section{RESULTS AND DISCUSSION}

Significance values and least squares means for all production parameters are included in Table 5.

\section{Efficacy of Algorithms}

DMI Responses. Dry matter intake was significantly affected by week $(P=0.02$; Table 5$)$ and tended to be affected by a 3 -way interaction between top dress, algorithm, and week $(P<0.07$; Table 5$)$. The effect of initial performance was not significant $(P=0.13$; Table 5). The significant relationship between DMI and week was expected because as weeks of the experiment progressed, the DIM of the cows increased. As lactation progresses and DIM of cattle increases, DMI typically declines after an initial spike postcalving (Martin and Sauvant, 2007). The cows used for this experiment were $231 \pm 23$ DIM at the beginning of the study and well past the initial DMI spike after calving. However, DMI in the current study did not follow a linear decrease and resembled random increases and reductions by week, when algorithms were updated, likely reflecting changes in supplemental feed provided. Figure 4 shows DMI responses by algorithm type and top dress used, by week. Overall, increased consumption was observed by the second week of the experiment, and decreases in DMI began around wk 4 of the experimental period (Figure 4). Positive and negative fluctuations were observed throughout the experimental weeks, but DMI by wk 5 of the experimental period was relatively similar to wk 1 (Figure 4). The 5-wk experimental period may not have been long enough to capture the expected decline in DMI as the stage of lactation advanced for these cows or algorithmic feeding strategies may have masked this decline.
Similar to the training-period data (Price et al., 2021), DMI tended to be affected by top dress, and a tendency for an interaction between top dress, algorithm, and week was identified $(P=0.07$; Table 5). Based on the contrasts, the only significant differences were associated with DMI reductions on algorithm 1 when cows were fed SBM in the first week $(P=0.02)$ and when cows were fed GH in the third week $(P=$ 0.009). Because these differences showed minimal patterning, we can expect they were more a reflection of random chance than of consistent trends. In general, the DMI for algorithm 1 in particular, although not significant, was consistently numerically lower than the control group, which requires further investigation. If confirmed, this might be a suggestion that this algorithm may have been picking up on opportunities to decrease feed intake while maintaining MY. Long-term depressed feed intake is likely to cause numerous production challenges, especially in early lactation where it could lead to increased body fat mobilization. Body fat mobilization in excess can lead to metabolic disorders, reproductive problems, and welfare issues (Weber et al., 2013), thus greatly affecting animal performance and economic efficiency of dairy operations. Thus, this approach is likely not desirable in a production setting. Future algorithms should alter response variable selection or treatment selection rules to promote maintenance of DMI while trying to affect changes in FE (i.e., focus on improving MY without affecting DMI). In this context, residual feed intake would be a promising measurement to be included in the algorithms because it does include cow BW, DIM, changes in BW, and BCS. Thus, predicting the top-dress feedstuff to reach lower residual feed intake could be more appropriate than milk:feed ratio is as a subject for future work.

Milk Yield. Milk yield was significantly affected by initial performance $(P<0.001$; Table 5$)$. The effects of top dress $(P=0.30$; Table 5$)$, algorithm $(P=0.44$; Table 5$)$, and week $(P=0.28$; Table 5$)$ were not significant. Figure 4 shows MY responses by algorithm type and top dress used, by week.

The significant relationship between MY and initial MY of the study was expected and likely reflects persistency of differences in animal genetic merit across feeding strategies. After accounting for DIM changes throughout the study, MY values of individual cows throughout the experimental period were similar to individual yield values from the beginning of the study. It was also expected that week and DIM would decrease MY. A typical lactation curve is characterized by a steady decline in MY toward the end of lactation (Wood, 1967). The algorithms and supplemental top dresses may have masked the expected decrease in MY as DIM increased throughout the study, but it is more 
Souza et al.: MODELS FOR INDIVIDUALIZED PRECISION FEEDING

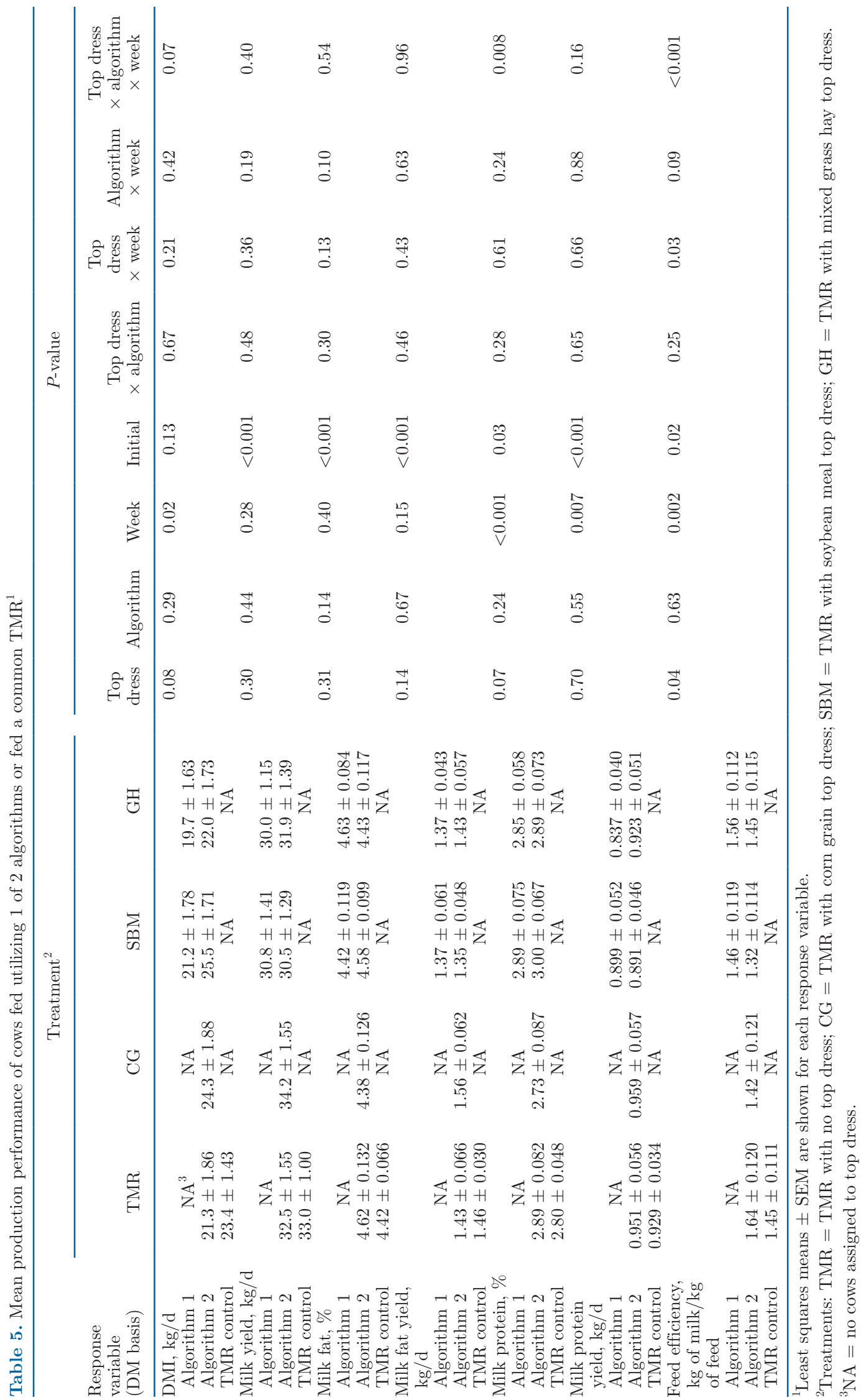



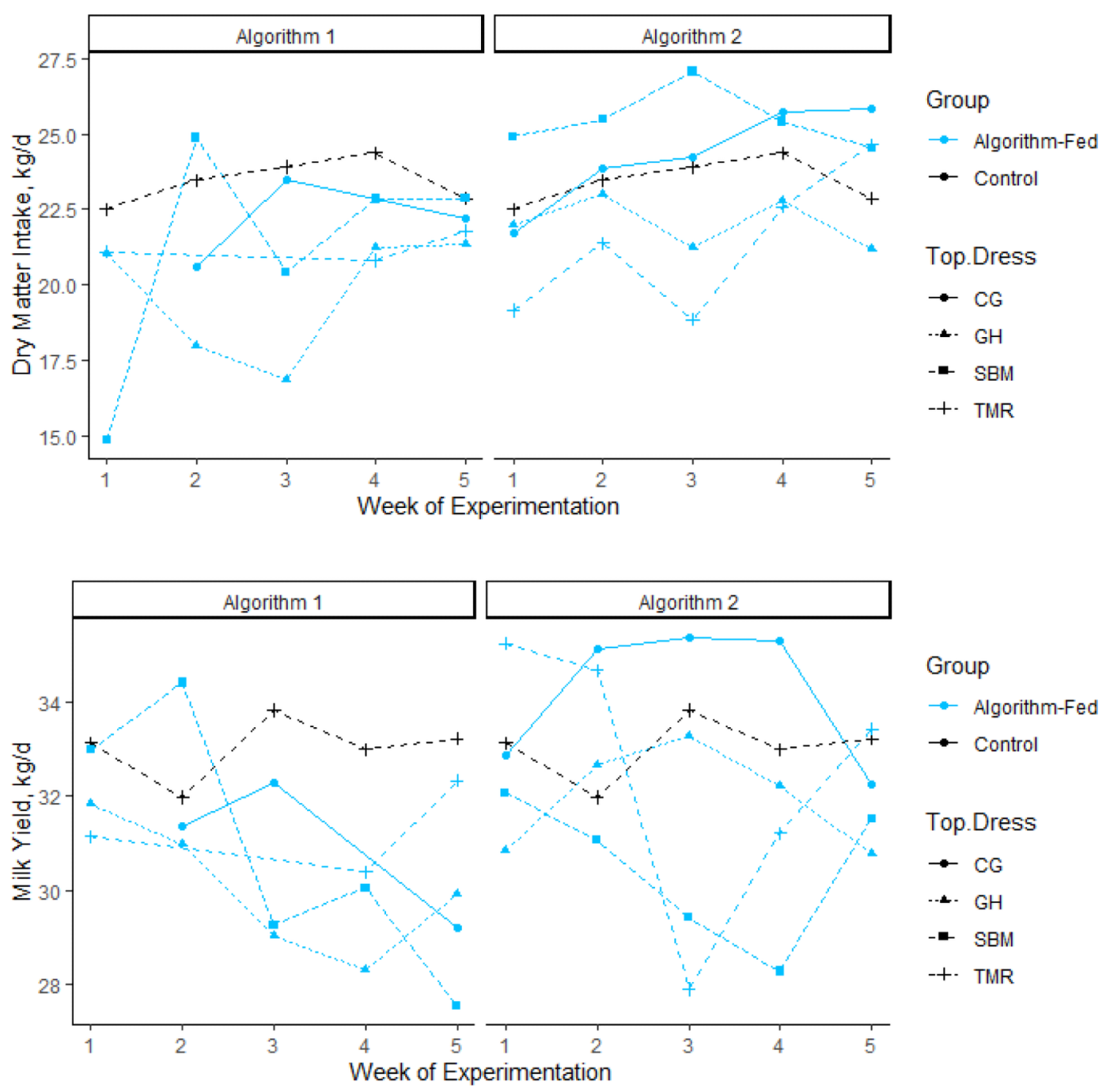

Figure 4. Least squares means of DMI (kg/d; top) and milk yield $(\mathrm{kg} / \mathrm{d}$; bottom) for each top dress $(\mathrm{CG}=\mathrm{corn}$ grain, $\mathrm{GH}=$ grass hay, $\mathrm{SBM}$ = soybean meal) predicted by each algorithm over the weeks of the experimental period. The colors of each line (shown in the Group legend) depict those animals fed via algorithm or those fed the control diet. The symbols of the different lines show the different feeds used as top dress for the animals (shown in the Top Dress legend). Because control animals were always exposed only to the TMR feed, the 5 lines represent an incomplete factorial of these factors, where algorithm-fed cows were exposed to all levels of top dress, but control cows were only exposed to TMR.

likely that the experimental period of the current study was not long enough to detect MY declines.

Milk yield was not affected by top dress or week, as it was in the training period (Price et al., 2021). In the training period, cows consuming CG and SBM diets had higher MY than in the current algorithm testing period (Price et al., 2021). One explanation for the lack of MY response to top dress is that algorithms developed in this study masked the effect of top dresses such as CG and SBM diets due to poor predictions of top-dress supplementation type or amount. The effect of week seen in the training period (Price et al., 2021) may not have been detected in the current study due to differences in DIM between the 2 studies. The ab- sence of top dress and week effects may also be caused by the algorithmic selection for FE, rather than MY. Future research on refined algorithm development is needed to influence MY through individualized feeding techniques. In particular, differences in the objective of algorithms should be tested. By selecting for FE, we possibly generated more modest responses in both MY and DMI than if we were to select for either individually or use another multi-objective response criterion selecting for both simultaneously without forcing a linear relationship (as is done in MY/DMI).

Milk Fat Percentage and Yield. Milk fat percentage was significantly affected by initial performance $(P$ $<0.001$; Table 5 ) and tended to be affected by a 2 -way 
interaction between algorithm and week $(P=0.10$; Table 5). The effect of top dress was not significant $(P=$ 0.31 ; Table 5). Milk fat yield was significantly affected by initial performance $(P<0.001$; Table 5$)$; however, it was not affected by top dress $(P=0.14)$, algorithm $(P=0.67)$, or week $(P=0.15)$. Figure 5 shows milk fat percentage and yield responses by algorithm type and top dress used, by week. It is not surprising that milk fat yield results mirrored the MY responses (Table 5). Based on these data, the 2 algorithms tested in this experiment were not effective at creating shifts in milk fat percentage or yield. Because the algorithms were not designed to influence milk fat percentage or yield, it is not surprising that changes in these performance responses were not detected.

Milk Protein Percentage and Yield. Milk protein percentage was significantly affected by a 3 -way interaction between top dress, algorithm, and week $(P=$ 0.008 ; Table 5$)$, and by initial performance $(P=0.03$; Table 5). Milk protein yield was significantly affected by week $(P=0.007$; Table 5$)$ and initial performance $(P<0.001$; Table 5$)$. The effects of top dress $(P=0.70$; Table 5) and algorithm $(P=0.55$; Table 5$)$ were not significant.
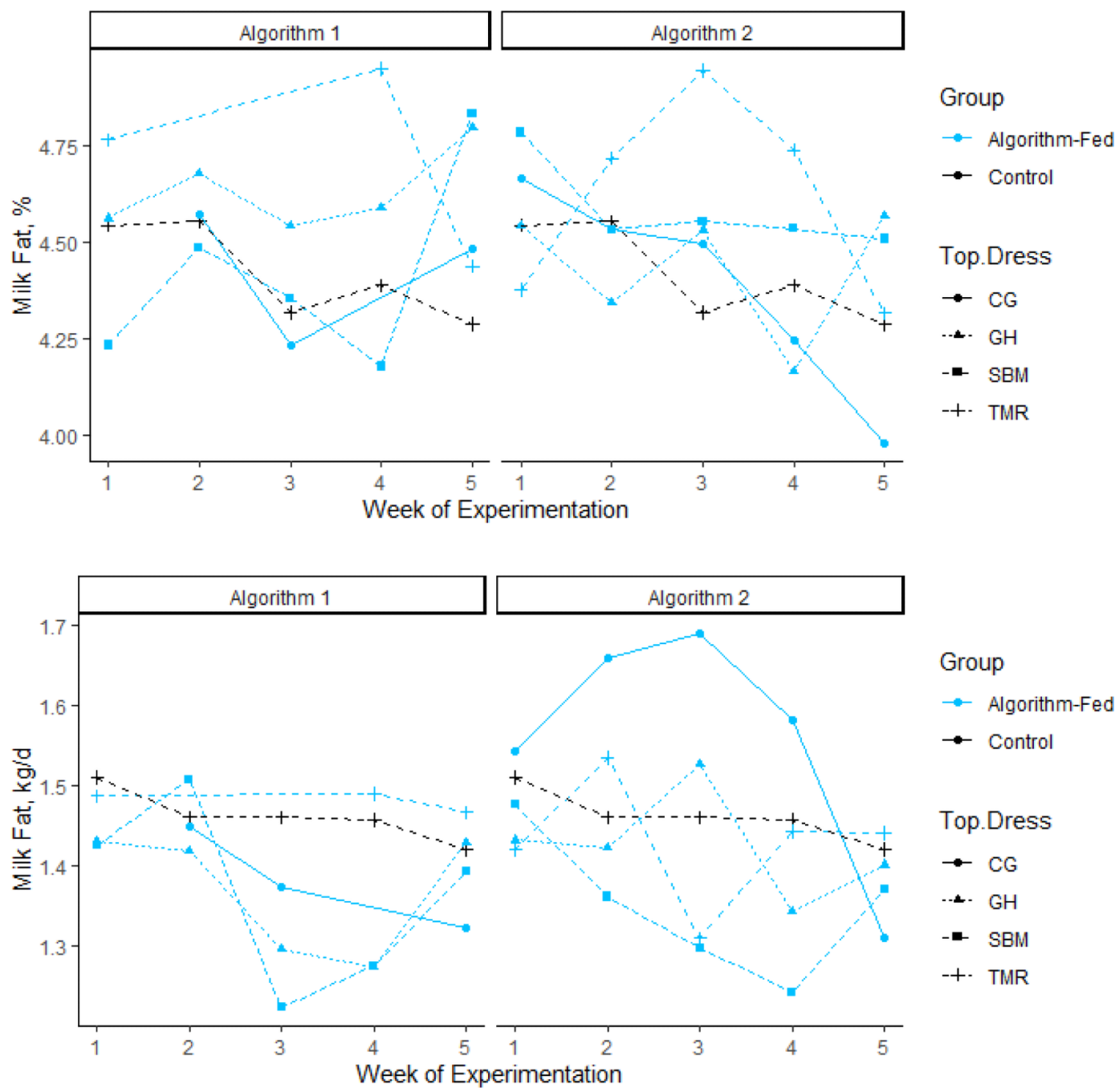

Figure 5. Least squares means of milk fat percentage (top) and yield (kg/d; bottom) for each top dress $(\mathrm{CG}=\mathrm{corn}$ grain, $\mathrm{GH}=$ grass hay, $\mathrm{SBM}=$ soybean meal) predicted by each algorithm over the weeks of the experimental period. The colors of each line (shown in the Group legend) depict those animals fed via algorithms or those fed the control diet. The symbols of the different lines show the different feeds used as top dress for the animals (shown in the Top Dress legend). Because the control animals were always exposed only to the TMR feed, the 5 lines represent an incomplete factorial of these factors, where algorithm-fed cows were exposed to all levels of top dress, but control cows were only exposed to TMR. 

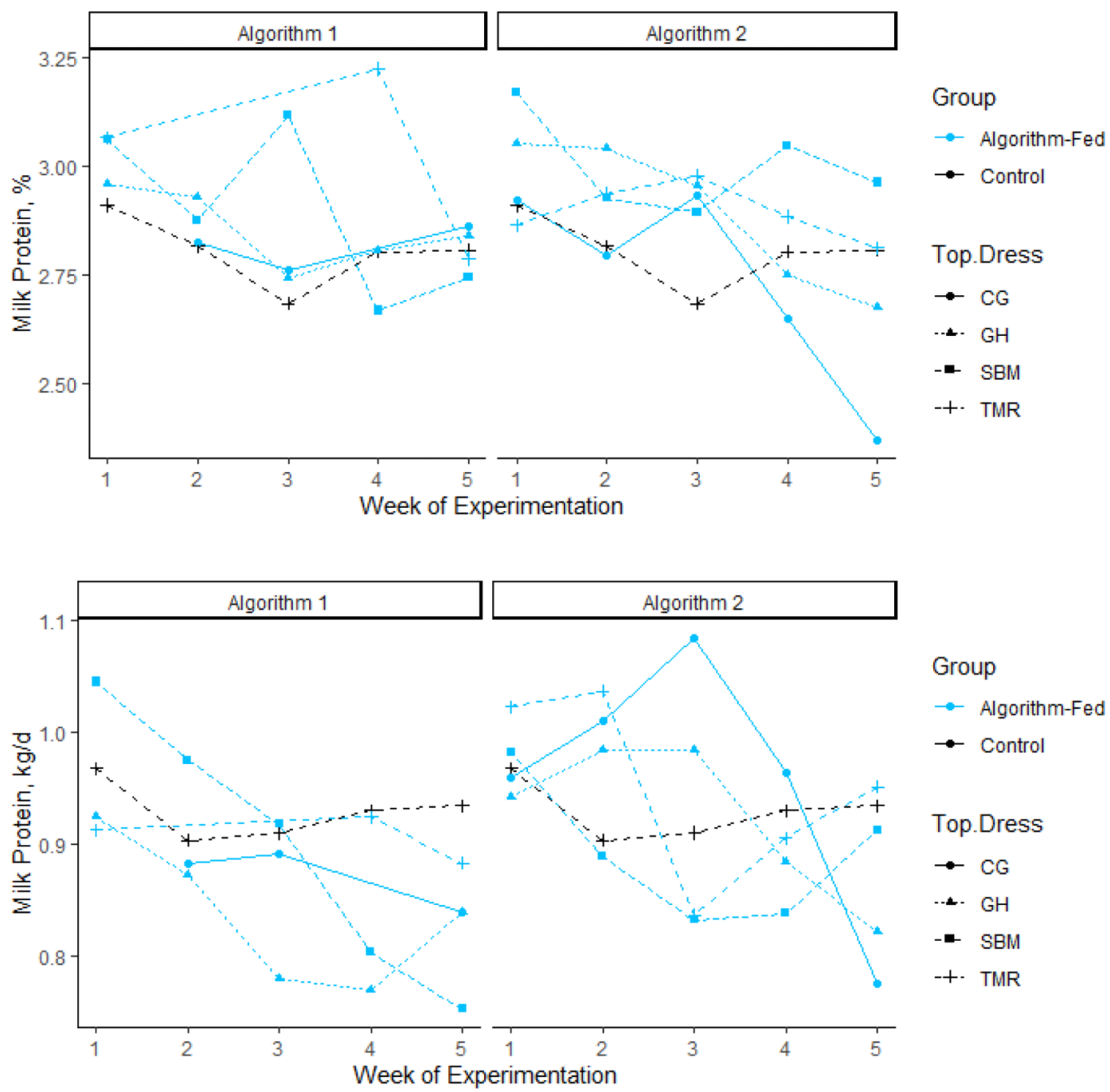

Figure 6. Least squares means of milk protein percentage (top) and yield (kg/d; bottom) for each top dress $(\mathrm{CG}=$ corn grain, $\mathrm{GH}=$ grass hay, SBM = soybean meal) predicted by each algorithm over the weeks of the experimental period. The colors of each line (shown in the Group legend) depict those animals fed via algorithms or those fed the control diet. The symbols of the different lines show the different feeds used as top dress for the animals (shown in the Top Dress legend). Because the control animals were always exposed only to the TMR feed, the 5 lines represent an incomplete factorial of these factors, where algorithm-fed cows were exposed to all levels of top dress, but control cows were only exposed to TMR.

Figure 6 shows milk protein percentage responses by algorithm type and top dress used, by week. This result suggests that individualized, precision feeding through top dressing has the ability to influence the protein percentage in milk. Top dressing with higher protein feeds was expected to increase milk protein synthesis (Kalscheur et al., 1999; Huhtanen and Hristov, 2009). Individualized algorithms need to be developed with consideration to the available feedstuff on farm to prevent decreases in MY or components while selecting for FE. Based on the contrasts, cows fed TMR predicted by algorithm 2 in wk $3(P=0.03)$, SBM predicted by algorithm 1 in wk $3(P=0.002)$, and TMR predicted by algorithm 1 in wh $4(P=0.02)$, resulted in significantly higher milk protein percentages when compared with cows fed ad libitum TMR. However, cows assigned TMR diets by the algorithms showed increases in milk protein percentage initially in the experimental period, but percentages at wk 5 were similar to milk protein percentages of cows fed ad libitum TMR (Figure 6). This suggests that algorithmic predictions for TMR may not be sustainable for increased milk protein percentages long-term. Cows fed GH predicted by algorithm 2 in wk $3(P=0.05)$ and CG predicted by algorithm 2 in wk 5 $(P=0.002)$ resulted in significantly lower milk protein percentages. As a result, $\mathrm{CG}$ and GH may not be ef- 


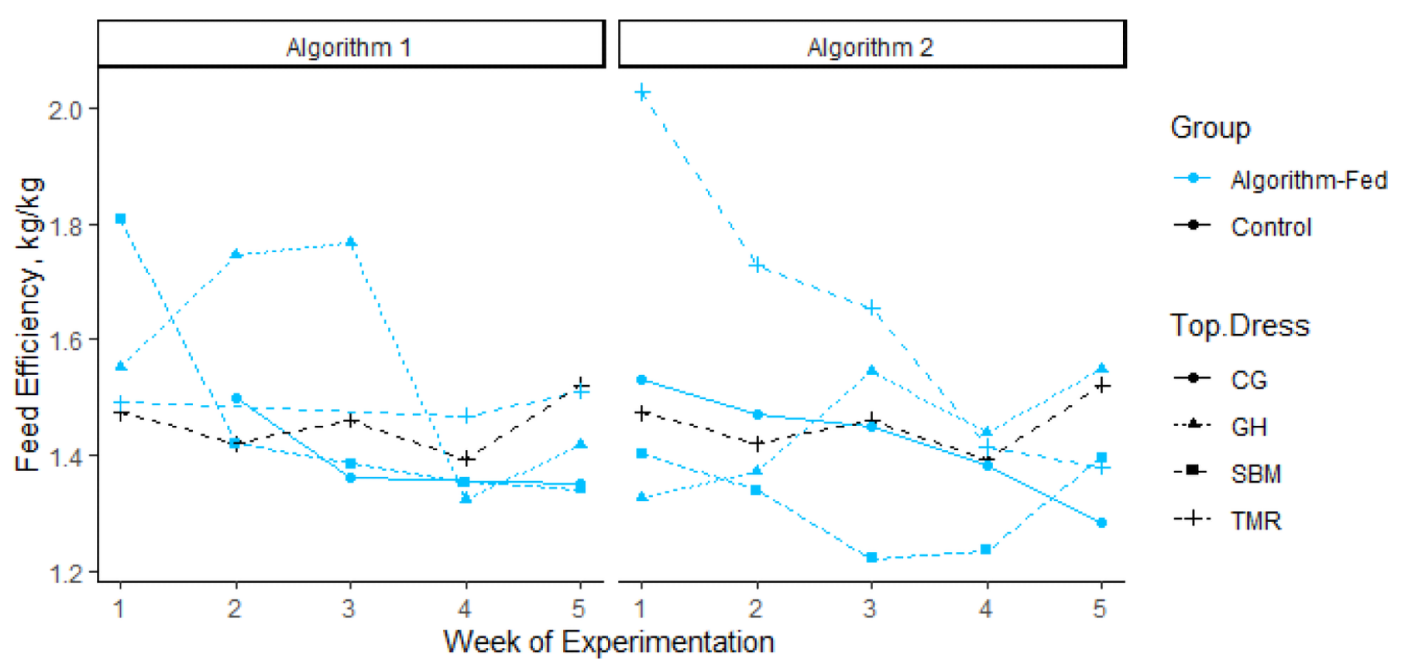

Figure 7. Least squares means of feed efficiency $(\mathrm{kg} / \mathrm{kg})$ for each top dress $(\mathrm{CG}=$ corn grain, $\mathrm{GH}=$ grass hay, $\mathrm{SBM}=$ soybean meal $)$ predicted by each algorithm over the weeks of the experimental period. The colors of each line (shown in the Group legend) depict those animals fed via algorithms or those fed the control diet. The symbols of the different lines show the different feeds used as top dress for the animals (shown in the Top Dress legend). Because the control animals were always exposed only to the TMR feed, the 5 lines represent an incomplete factorial of these factors, where algorithm-fed cows were exposed to all levels of top dress, but control cows were only exposed to TMR.

fective top dresses to use under algorithm 2 because of their steady decline in milk protein percentage by wk 3 of the experimental period (Figure 6).

As expected, cows fed SBM, particularly under algorithm 2, showed the highest milk protein percentage (Table 5), largely due to the high protein concentration of this top dress (Table 4). It was also expected that DIM, and therefore week, would cause milk protein percentage to increase as lactation progressed (Linn, 1988). However, milk protein percentage generally decreased over the experimental period (Figure 6). Current algorithms may have contributed to the unexpected decrease in milk protein percentage by making poor assignments of individual animals to specific topdress types and quantities. Another explanation for the unexpected decrease in milk protein percentage could be that the base TMR may have been deficient in MP. However, this is unlikely because the base TMR used in this experiment is the sole feed fed on this particular dairy operation. The TMR was formulated to provide 2,750 g of MP per day (Table 1), which is an acceptable MP amount for large-breed cattle producing at this level (NRC, 2001). Initial performance also had a significant effect on milk protein percentage $(P=$ 0.03; Table 5) and suggests unique genetic thresholds of individual animals. In general, these results highlight the potential of individualized feeding with these algorithm techniques to affect the protein percentage of milk by supplementing individual cows with various top dresses. Future research focused on fine tuning the development, and training of algorithms may increase milk protein percentage of individual animals.
Milk protein yield was significantly affected by week $(P=0.007$; Table 5$)$ and initial performance $(P$ $<0.001$; Table 5). Figure 6 shows milk protein yield responses by algorithm type and top dress used, by week. In the current study, milk protein yield decreased over the course of the experiment (Figure 6). Changes in milk protein yield were associated with time, and week effect was consistent with stage of lactation (Linn, 1988). Similarly, DMI was also affected by week. Decreased DMI over the weeks of this experiment may have contributed to lower milk protein yields, as well. The algorithms used in this experiment were able to increase milk protein percentage, but not milk protein yield. However, continuing to develop and train these algorithms, over time, may have greater influence on milk protein yield through individualized feeding.

Feed Efficiency. As expected, FE was affected by many factors. A 3-way interaction between top dress, algorithm, and week exists $(P<0.001$; Table 5$)$. Feed efficiency was also significantly affected by initial performance $(P=0.02$; Table 5$)$. Figure 7 shows FE responses by algorithm type and top dress used, by week.

The 3-way interaction between top dress, algorithm, and week $(P<0.001$; Table 5$)$ suggests that individualized feeding of top-dress supplements has the ability to affect FE of dairy cattle. Based on the contrasts, cows fed SBM from algorithm 2 predictions in wk 4 of the experimental period showed significantly decreased feed efficiencies when compared with cows fed TMR ad libitum $(P=0.04)$. However, cows fed TMR diets assigned by algorithm 2 resulted in the highest feed efficiencies (Table 5). The developed algorithms were capable of 
influencing FE, but refined models and algorithm training may reflect higher efficiencies of all supplemental interventions when compared with cows fed solely TMR. As a part of this interaction, FE was also affected by week; it was expected for $\mathrm{FE}$ to decrease as lactation progressed (St-Pierre, 2008). In general, FE decreased over the experimental period, but this decrease was not uniform across all top dresses (Figure 7). Unexpectedly, cows fed TMR ad libitum experienced slight increases in FE (Figure 7). The length of the experimental period may not have been long enough to capture the expected decrease in efficiency. This interaction suggests that the developed algorithms are capable of influencing FE by supplementing individual animals with various top dresses. However, more efficient algorithms need to be developed to maximize individual efficiencies.

\section{Financial Extrapolation of Model Outcomes}

Table 6 shows the financial implications of feeding the different algorithms, standardized per number of animal days per treatment. Although few statistical differences in animal performance were observed, the milk revenues on the algorithm-fed cows (both algorithms 1 and 2) were numerically greater than on the control-fed cows (Table 6). Similarly, the feed costs of the algorithm-fed cows totaled less than those incurred by feeding TMR only. The net result, for the cumulative feeding groups, was that cows in the algorithm 2 group earned over $\$ 0.70$ more per head per day in comparison to cows on the TMR control. Cows on algorithm 1 earned roughly $\$ 0.45$ more per head per day in comparison to TMR-fed animals. These differences in milk revenues over feed costs represents considerably greater value retained from milk sales in algorithm-fed cows. Despite the numerical differences, no statistical analysis was performed on these data because, when calculated financial values are calculated for each feeding group, $n=1$. As such, the estimates here may be an overstatement of the financial benefits of individualized feeding strategies due to the short-term nature of this study, and the relatively small-scale implementation of the strategy. Nevertheless, the data suggest that there is opportunity to consider whether individualized feeding strategies may be beneficial for short-term implementation in targeted portions of the lactation curve when lower-cost strategies are desired and milk yields are less elastic to nutrient supplies.

\section{Relevance for Future Work and Limitations}

Short-term algorithm training was used in this experiment because longer-term training techniques would end further into lactation, and the amount of time individualized feeding could occur would be reduced. Feeding recommendations created though algorithm development may not apply to the subsequent lactation, as well. Future research on the minimal training period length needed to create efficient algorithms is warranted and will ensure maximum on-farm production.

Despite the lack of statistical significance on performance results observed in this study, individualized feeding through the use of precision technologies shows promise to affect positively economic efficiency of dairy operations. As such, we likely require additional future studies to determine the value (if any) of this technique on MY, milk components, and FE. Future development of individual cow response data to a multitude of top-dress feedstuffs is necessary to inform modeling exercises. Extensive research is also needed to develop algorithms capable of targeting specific production parameters that may be of interest for various dairy operations. Algorithms also need to be developed to be capable of feeding a wide variety of top dresses because commodity type and cost vary by location.

The feasibility of individualized feed management is still a challenge in large dairy operations because of the lack of reliable and cost-effective on-farm methods for measuring DMI (Huhtanen et al., 2021). However, the use of automatic in-parlor feeding systems and similar automated feed supplementation stations, which allow producers to feed cows with partial mixed rations individually, may be a possibility to overcome this challenge. This approach has tremendous environmental

Table 6. Financial analysis of feed costs and milk revenues under different feeding approaches

\begin{tabular}{lccc}
\hline & \multicolumn{3}{c}{ Feeding strategy } \\
\cline { 2 - 4 } Item $^{1}$ & Control & Algorithm 1 & Algorithm 2 \\
\hline TMR quantity, kg/d & 55.5 & 48.5 & 46.0 \\
TMR cost, \$/head per day & 12.21 & 10.67 & 10.11 \\
Corn quantity, kg/d & - & 1.34 & 1.52 \\
Corn cost, $\$$ /head per day & - & 0.31 & 0.35 \\
Soybean quantity, kg/d & - & 1.66 & 2.26 \\
Soybean cost, $\$ /$ head per day & - & 0.72 & 0.98 \\
Hay quantity, kg/d & - & 0.55 & 1.76 \\
Hay cost, $\$ /$ head per day & - & 0.09 & 0.29 \\
Milk production, kg/d & 31.0 & 31.1 & 31.6 \\
Milk receipts, $\$ /$ head per day & 12.26 & 12.30 & 12.50 \\
Feed cost, $\$ /$ head per day & 12.21 & 11.80 & 11.73 \\
IOFC, ${ }^{2} \$$ /head per day & 0.051 & 0.50 & 0.77 \\
\hline
\end{tabular}

${ }^{1}$ Actual purchase costs for TMR $(\$ 0.22 / \mathrm{kg})$, corn grain $(\$ 0.231 / \mathrm{kg})$, soybean meal $(\$ 0.434 / \mathrm{kg})$, and grass hays $(\$ 0.165 / \mathrm{kg})$ fed on the study were used to estimate feed costs; receipts for milk sales $(\$ 0.396 / \mathrm{kg})$ were used to estimate milk revenues. Market source used for feed commodities was from Big Spring Mill (Elliston, VA). Milk prices were those paid by the State of Virginia under an annually negotiated contract.

${ }^{2}$ Milk income over feed costs (IOFC). 
and economic benefits compared with the standard approach of feeding cows as a group in collective pens because it could allow the nutritionist to avoid under- or overfeeding of cows, which commonly occurs in group-feeding situations because of the natural variability observed in production and feed conversion, even for herds that group cows by DIM or production level. Gargiulo et al. (2018) showed in a survey-based study conducted in Australia that the majority (i.e., more than $84 \%$ ) of large dairy operations have access to automatic in-parlor feeding systems. Despite the lack of updated national data in the United States, we expect that large dairy operations in the United States may follow similar trends.

The models explained the vast majority of variation in FE through the training period; however, the responses to dietary interventions within individual animals between the training period and testing period often differed, meaning that adequate and accurate prediction of the data obtained during the training period did not confer accuracy to predicting FE during the testing period. Essentially, it does not appear that an individual animal's short-term response to dietary interventions is particularly repeatable, at least in our data set. Despite the potential poor predictions, the algorithms developed in this study present a first step to assess how we can use on-farm data to learn strategies to improve $\mathrm{FE}$ of animals.

The purpose of the current work was to evaluate what types of improvements we could enact in a "best case" feeding scenario where we actually could train algorithms on farm (thus generating analytics that are probably more accurate and precise than generally trained algorithms applied to a specific group of cattle). Therefore, the algorithms presented here would undoubtedly require evaluation and improvement in a wide range of additional production settings and crossevaluated in a large number of animals, especially in early lactation cows, before we could have confidence in their autonomous operation. However, they did result in economic benefit, which warrants longer-term and larger-scale evaluation as a next step.

\section{CONCLUSIONS}

Individualized feeding of dairy cattle shows promise to influence MY, milk components, and FE through significance in some overall effects and interactions. However, minimal meaningful significance was observed between the algorithms and the TMR control. Some top-dress treatments worked better under each algorithm, but no unilateral improvement was observed with the 2 algorithms developed in this experiment when compared with feeding TMR alone. As a result, future research on more refined model development and training is needed to influence individual cow MY, milk components, and FE.

\section{ACKNOWLEDGMENTS}

We gratefully acknowledge financial support from the National Science Foundation and the United States Department of Agriculture (grant no. 2018-67007-28452, Washington, DC), and the São Paulo Research Foundation (FAPESP; grant no. 2019/09201-5, São Paulo, Brazil). The authors have not stated any conflicts of interest.

\section{REFERENCES}

AOAC (Association of Official Analytical Chemists). 1990. Official Methods of Analysis. 15th ed. Association of Official Analytical Chemists.

Bach, A., and V. Cabrera. 2017. Robotic milking: Feeding strategies and economic returns. J. Dairy Sci. 100:7720-7728. https://doi .org/10.3168/jds.2016-11694.

Borchers, M. R., and J. M. Bewley. 2015. An assessment of producer precision dairy farming technology use, prepurchase considerations, and usefulness. J. Dairy Sci. 98:4198-4205. https://doi .org $/ 10.3168 / \mathrm{jds} .2014-8963$.

Castro, A., J. M. Pereira, C. Amiama, and J. Bueno. 2012. Estimating efficiency in automatic milking systems. J. Dairy Sci. 95:929-936. https://doi.org/10.3168/jds.2010-3912.

Eastwood, C. R., J. G. Jago, J. P. Edwards, and J. K. Burke. 2016. Getting the most out of advanced farm management technologies: Roles of technology suppliers and dairy industry organisations in supporting precision dairy farmers. Anim. Prod. Sci. 56:1752-1760. https://doi.org/10.1071/AN141015.

El-Osta, H. S., and M. J. Morehart. 2000. Technology adoption and its impact on production performance of dairy operations. Rev. Agric. Econ. 22:477-498. https://doi.org/10.1111/1058-7195.00034.

Gargiulo, J. I., C. R. Eastwood, S. C. Garcia, and N. A. Lyons. 2018. Dairy farmers with larger herd sizes adopt more precision dairy technologies. J. Dairy Sci. 101:5466-5473. https://doi.org/10 .3168/jds.2017-13324.

Guinguina, A., T. Yan, P. Lund, A. R. Bayat, A. L. F. Hellwing, and P. Huhtanen. 2020. Between-cow variation in the components of feed efficiency. J. Dairy Sci. 103:7968-7982. https://doi.org/10 $.3168 /$ jds.2020-18257.

Huhtanen, P., A. Bayat, P. Lund, and A. Guinguina. 2021. Residual carbon dioxide as an index of feed efficiency in lactating dairy cows. J. Dairy Sci. 104:5332-5344. https://doi.org/10.3168/jds 2020-19370.

Huhtanen, P., and A. N. Hristov. 2009. A meta-analysis of the effects of dietary protein concentration and degradability on milk protein yield and milk N efficiency in dairy cows. J. Dairy Sci. 92:32223232. https://doi.org/10.3168/jds.2008-1352.

Kalscheur, K. F., J. H. Vandersall, R. A. Erdman, R. A. Kohn, and E. Russek-Cohen. 1999. Effects of dietary crude protein concentration and degradability on milk production responses of early, mid, and late lactation dairy cows. J. Dairy Sci. 82:545-554. https://doi .org/10.3168/jds.S0022-0302(99)75266-5.

Linn, J. G. 1988. Factors Affecting the Composition of Milk from Dairy Cows. in Designing Foods: Animal Product Options in the Marketplace. National Academies Press.

Martin, O., and D. Sauvant. 2007. Dynamic model of the lactating dairy cow metabolism. Animal 1:1143-1166. https://doi.org/10 .1017/S1751731107000377. 
NRC. 2001. Nutrient Requirements of Dairy Cattle. 7th rev. ed. National Academies Press.

Price, T. P., V. C. Souza, D. M. Liebe, M. D. Elett, T. C. Davis, C. B. Gleason, K. M. Daniels, and R. R. White. 2021. Short-term adaptation of dairy cattle production parameters to individualized changes in dietary top dress. Animals (Basel) 11:3518. https://doi . org/10.3390/ani11123518.

ServiTech Laboratories. 2021. Feed sampling procedures. Accessed Mar. 27, 2019. https://servitechlabs.com/Services/Feed/ FeedSamplingProcedures/tabid/126/Default.aspx.

St-Pierre, N. R. 2008. Managing Measures of Feed Costs: Benchmarking Physical and Economic Feed Efficiency. Pages 99-112 in TriState Dairy Nutrition Conference. Ohio State University, Columbus.

Wang, S. J., D. G. Fox, D. J. R. Cherney, L. E. Chase, and L. O. Tedeschi. 2000. Whole-herd optimization with the Cornell net carbohydrate and protein system. III. Application of an optimization model to evaluate alternatives to reduce nitrogen and phosphorus mass balance. J. Dairy Sci. 83:2160-2169. https://doi.org/10 .3168/jds.S0022-0302(00)75099-5.
Weber, C., C. Hametner, A. Tuchscherer, B. Losand, E. Kanitz, W. Otten, S. P. Singh, R. M. Bruckmaier, F. Becker, W. Kanitz, and H. M. Hammon. 2013. Variation in fat mobilization during early lactation differently affects feed intake, body condition, and lipid and glucose metabolism in high-yielding dairy cows. J. Dairy Sci. 96:165-180. https://doi.org/10.3168/jds.2012-5574.

White, R. R., and J. L. Capper. 2014. Precision diet formulation to improve performance and profitability across various climates: Modeling the implications of increasing the formulation frequency of dairy cattle diets. J. Dairy Sci. 97:1563-1577. https://doi.org/ 10.3168/jds.2013-6859.

Wood, P. D. P. 1967. Algebraic model of the lactation curve in cattle. Nature 216:164-165. https://doi.org/10.1038/216164a0.

Zanton, G. and J. Heinrichs. 2008. Precision feeding dairy heifers: Strategies and recommendations. Accessed Dec. 17, 2021. https:/ /www.extension.iastate.edu/dairyteam/files/page/files/limit-feed -dairy-heifers-08-130.pdf. 